\title{
MUCOCELE FRONTAL COM EXTENSÃO INTRACRANIANA. A PROPÓSITO DE DOIS CASOS
}

\author{
Oswaldo Ricciardi Cruz *
}

O mucocele frontal è relativamente freqüente; entretanto, sua extensão intracraniana, determinando compressão do lobo frontal, é rara. Em nosso meio vários autores registraram casos de mucocele dos seios paranasais (Cruz ${ }^{1}$, Matheus ${ }^{3}$, Matheus e col.4), entretanto não encontramos registro de caso com extensāo intracraniana. Werner e Vitte ${ }^{5}$ registraram um caso de localização frontal com extensão intracraniana e palpebral, chamando a atenção para a riqueza semiológica, assim como para a raridade do processo como causa de compressāo cerebral.

O mucocele frontal é um tumor encapsulado, de limites precisos, constitituído pelo acúmulo, lento e progressivo, do produto secretado pela mucosa do seio frontal obstruído; em certos casos a tumoração destrói as paredes ósseas do seio, invadindo a caixa craniana e as estruturas vizinhas. Em que pese a hipótese congênita, a etiologia obstrutiva é a mais credenciada; a obstrução - traumática, tumoral ou hiperplásica - do canal naso-sinusal, determinaria condições para a insulação da mucosa do seio frontal, com conseqüente distensão progressiva do cisto pela contínua secreção, não drenada, das glândulas mucosas.

Registrando dois casos de mucocele frontal com extensão intracraniana visamos chamar a atenção para êsse processo como causa de compressão cerebral.

\section{OBSERVAÇOES}

Caso 1 - M. M. S., com 37 anos de idade, prêto, sexo masculino, internado na Clinica Cirúrgica do Hospital Municipal em 29-7-1958 (Reg. 46.426). Há 2 meses, protusão e dor no globo ocular esquerdo, irradiando-se para a regiāo frontal; ao mesmo tempo diminuiçāo progressiva da acuidade visual do ôlho esquerdo. $\mathrm{O}$ exame clinico apenas mostrou exoftalmo à esquerda; exame neurológico negativo. Radiografias do crânio: lesão osteolitica que atinge o teto da órbita, o rebordo orbitário e pequena extensão do osso frontal acima do rebordo orbitârio esquerdo (fig. 1). Exame do liqüido cefalorraquidiano: punção suboccipital com o paciente deitado; pressāo inicial $24 \mathrm{~cm}$ de água (manômetro de Claude), pressāo final 4; proteinas $32 \mathrm{mg} / 100 \mathrm{ml}$; cloretos $700 \mathrm{mg} / 100 \mathrm{ml}$; glicose $48 \mathrm{mg} / 100 \mathrm{ml}$; o restante sem anormalidades. Angiografia cerebral via artéria carotida esquerda: vasos cerebrais de trajeto e calibre normais; nāo há sinais de circulaçāo patológica.

Trabalho da Clínica Neurológica da Fac. Med. da Univ. de São Paulo (Prof. A. Tolosa). *Assistente extranumerário. 
Fig. 1 - Caso 1 (M. M. S.). Radiografia do crânio mostrando área de osteólise ao nível do teto da órbita, do rebordo orbitário e de pequena extensão do osso frontal esquerdo.

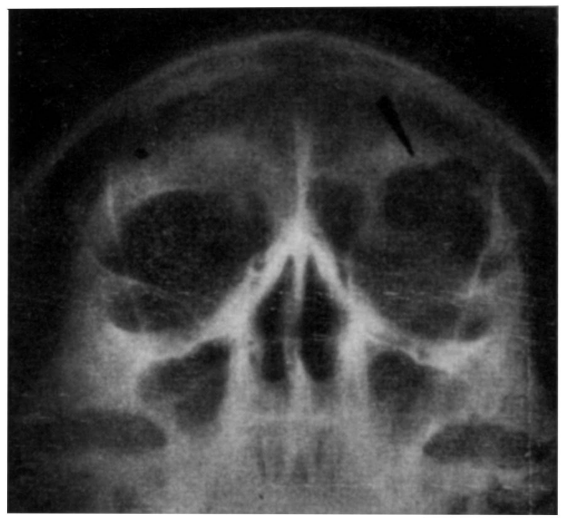

Operação - Craniotomia osteoplástica frontal esquerda. Após o levantamento do retalho cutâneo, surgiu, ao nível do rebordo orbitário, uma tumoração de $2 \mathrm{~cm}$ de diâmetro próximo à emergência do nervo supra-orbitário. Ao ser levantado o retalho ósseo, foi observado um tumor cístico de $3 \mathrm{~cm}$ de diâmetro aderente à dura máter do pólo frontal que era deslocado para trás e para cima. O descolamento das aderências do cisto com a meninge provocou a rotura da cápsula, dando saída a um líqüido de côr marron, pouco viscoso. O tumor invadia e destruia o osso frontal próximo ao teto da órbita e empurrava o globo ocular para frente. Rethrada a cápsula do cisto, foi curetada a cavidade residual assim como a mucosa do seio frontal. Ampla drenagem foi estabelecida com a cavidade nasal.

Evoluç̃o - Nenhuma intercorrência no pós-operatório, tendo regredido o exoftalmo. O paciente teve alta hospitalar, assintomático, em 20-10-1958. Exame feito após 1 ano revelou normalidade das condiçoes clínicas e locais.

Caso 2 - B. C. F., com 50 anos de idade, prêta, sexo feminino, internada na Clínica Neurológica do Hospital das Clinicas em 27-7-1959 (Reg. 560.841). Há 3 anos aparecimento de pequena tumoração no ângulo medial do ôlho esquerdo; ulteriormente, com o crescimento progressivo da tumoracāo, exoftalmo associado a dor e perda da acuidade visual à esquerda. O exame clínico apenas mostrava grande exoftalmo com desvio do globo ocular esquerdo para fora e para baixo (fig. 2). Radiografias do crânio: cavidade orbitária esquerda consideràvelmente au-

Fig. 2 -Caso 2 (B. C. F.). Exoftalmo e desvio do globo ocular esquerdo para fora e para baixo.

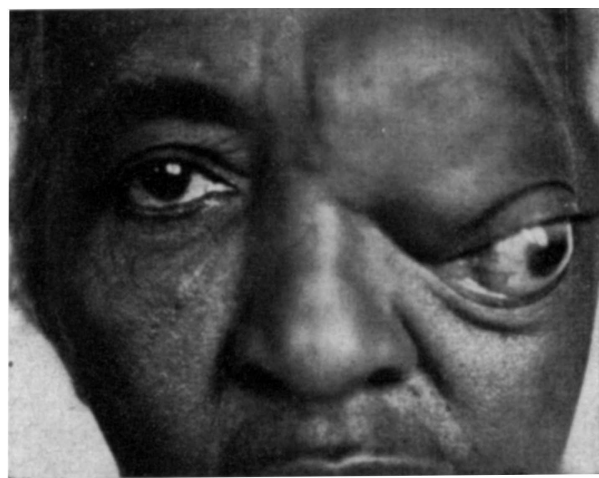


mentada, com diâmetro médio de $8 \mathrm{~cm}$, tendo seu limite superior deslocado para cima $(3 \mathrm{~cm})$ em relação ao lado oposto; o limite medial ultrapassa a linha média e se avizinha da parede orbitária supramedial do lado oposto; o limite lateral da cavidade é regular e ligeiramente abaulado (fig. 3). Exame do líqüido cefalorra-
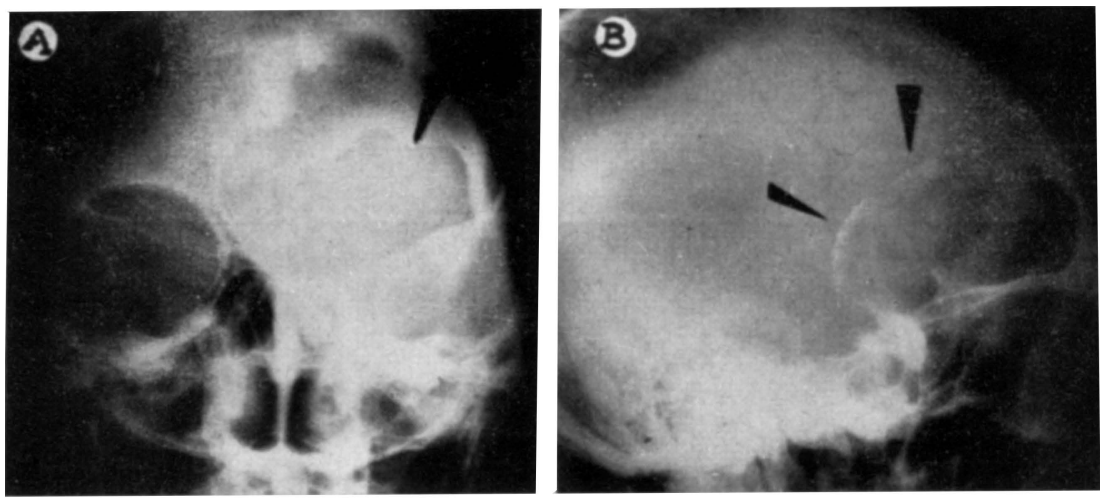

Fig. 3 - Caso 2 (B. C. F.). Em A, radiografia ântero-posterior mostrando aumento da cavidade orbitaria esquerda com extensa zona de osteólise; em $B$, incidência lateral quc evidencia o desiocamento do teto da órbita para cima.

quidiano: punção suboccipital com o paciente deitado; pressão inicial $12 \mathrm{~cm}$ de água (manômetro de Claude), pressão final $2 ; 10$ leucócitos por $\mathrm{mm}^{3}$ (100\% de linfócitos); - restante sem anormalidades. Angiografia cerebral via artéria carótida esquerda; acentuado desvio da artéria cerebral anterior para a direita e para trás; acentuado desvio da artéria oftálmica para baixo, formando uma curva de concavidade voltada para cima (fig. 4). Electrencefalograma normal.
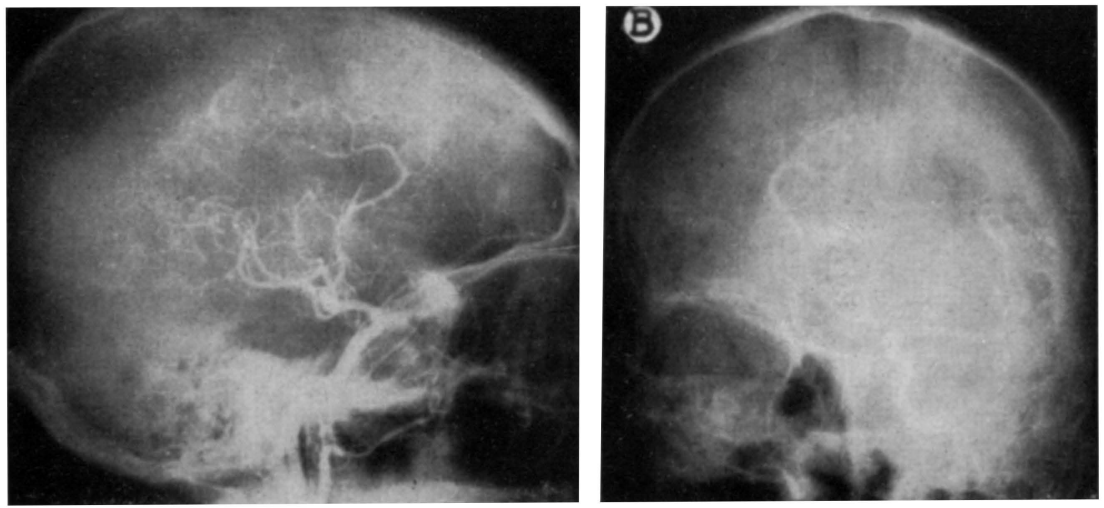

Fig. 4 - Caso 2 (B. C.F.). Angiografia cerebral via artéria carótida esquerda indicando a existência de processo expansivo na regiro fronto-orbitária. 
Operação - Craniotomia osteoplástica frontal esquerda, permitindo expor um cisto contendo aproximadamente $200 \mathrm{~cm}^{3}$ de muco viscoso e de côr esverdeada, que, provindo do seio frontal, delaminava o teto da órbita, elevando-o, e deslocava o pólo frontal para cima e para a direita e o globo ocular para fora. Após a retirada da coleçāo mucosa foi feita a curetagem e electrocoagulação da parede do cisto. A retirada do muco permitiu recolocar o teto da órbita em sua topografia normal, deixando, entretanto, uma falha na dura máter (correspondente à extensão dessa membrana em contato com a base da fossa anterior), que foi substituida por um enxêrto de fascia lata.

Evolução - Nenhuma intercorrência no pós-operatório; regressão do exoftalmo. A paciente teve alta hospitalar, assintomática, em 19-8-1959. O exame do líqüido cefalorraquidiano feito nessa ocasião foi normal. Exame feito 8 meses após mostrou normalidade das condições clinicas e locais.

\section{COMENTARIOS}

São vários os aspectos que devem ser ressaltados nestes dois casos de mucocele frontal com extensão intracraniana. A semelhança da sintomatologia clínica, em desacôrdo com o desenvolvimento do processo tumoral, é o primeiro aspecto a ser realçado; no caso 1, o tumor apresenta um têrço do volume da tumoração observada no caso 2 , havendo sòmente proporção em relação ao grau de exoftalmo, pois, no caso 2 a projeção do globo ocular era três vêzes maior que no caso 1 . A disparidade e aparente incongruência dos exames complementares merece realce: no primeiro caso a punção raquidiana mostrou haver hipertensão intracraniana, ao passo que a arteriografia cerebral foi normal; o oposto se verificou no caso 2 , no qual não havia hipertensão liquórica enquanto que a arteriografia revelava extenso processo expansivo localizado na fossa anterior.

$O$ aspecto e a consistência do conteúdo mucoso represado no cisto também eram diversos: em um caso o material era de côr marron e pouco viścoso, ao passo que, no outro, era de côr verde e intensamente viscoso; essa variabilidade das condições físicas do conteúdo dos mucoceles é interpretada, por Fliss e col. ${ }^{2}$, como a expressão de diferentes fases de um mesmo processo.

Em ambos os casos foi usada a abordagem frontal - craniotomia osteoplástica - com ótimos resultados. No caso 2 , a retirada da coleção mucosa por via externa, além de ser extremamente difícil, dado o volume e a consistência da tumoração, não permitiria o tempo cirúrgico intracraniano (correção do teto da órbita e plástica da dura máter), que reputamos tão importante quanto a drenagem por via nasal preconizada pela maioria dos autores. A auto-esterilização do muco no caso 2 está perfeitamente demonstrada, pois, a despeito do amplo contato, durante o ato cirúrgico, dêsse material com a corticalidade do lobo frontal nāo ocorreu qualquer processo irritativo meningencefalítico, como atestam a evolução do caso e a normalidade do líqüido cefalorraquidiano feito após a intervenção. 
RESUMO

$O$ autor apresenta dois casos de mucocele frontal com extensão intracraniana. Em um dos casos existia hipertensão intracraniana e quadro angiográfico normal; no outro, os valores tensionais do liqüido cefalorraquidiano eram normais e o exame angiográfico demonstrou a presença de um tumor de localização frontal. Em ambos os casos foi utilizada a via frontal craniotomia osteoplástica - para o acesso intracraniano. O contato do material contido no cisto com as meninges não determinou alterações meningencefaliticas.

\section{SUMMARY}

Mucocele of the frontal sinus with intracranial extension.

Two cases of mucocele of the frontal sinus with intracranial extension are presented. In one of them there was intracranial hipertention without changes in the cerebral angiographic patterns; in the other, the values of the spinal fluid pressure were normal and the angiography showed frontoorbital tumor. For surgery a frontal approach was made in both cases.

\section{REFERENCIAS}

1. CRUZ, N. A. - Mucocele frontal; três casos. Rev. Brasil. de Cir., 35:197, 1958. 2. FLISS, A.; WASSERMANN, L.; BUIUC, S.; OSTAP, B. - Etude sur les formes anatomo-cliniques et la pathologie de la mucocele fronto-ethmoidale. Ann. Otolaringol., 74:947, 1957. 3. MATHEUS, F. B. - Mucocele do seio maxllar. Rev. Brasil. de Otorrinolaringol., 20:51, 1952. 4. MATHEUS, F. B.; CORREA, A.; BARBOSA, J. F.; HIRSCHMAN, J. - Mucocele frontal (a propósito de 6 casos). Rev. Brasil. de Otorrinolaringol,, 17:24, 1949. 5. WERNER, J.; VITTE, G. - Mucocele frontale à extension palpebrale et endocranjenne. Rev. Oto-Neuro-Ophtalmol., 30: $362,1958$.

Glinica Neurológica - Hospital das Clinicas da Fac. Med. da Univ. de São Paulo - Caixa Postal 3461 - São Paulo, Brasil. 